\title{
Polysulfide Poisoning of Ag Electrocatalyst during L-Ascorbate Ion Electro-oxidation in Alkaline Solution
}

\author{
Fereydoon GOBAL, Laleh MAJARI KASMAEE \\ Department of Chemistry, Sharif University of Technology, P.O. Box 11365-9516, Tehran, Iran
}

\begin{abstract}
L-Ascorbate anion electro-oxidation on a silver electrode in hydroxide solution in the absence and presence of sodium polysulfide of concentrations from $1 \times 10^{-5}$ to $4.5 \times 10^{-4} \mathrm{~mol} / \mathrm{L}$ was studied using cyclic voltammetry and electrochemical impedance spectroscopy. Both hydroxide and polysulfide ions inhibited L-ascorbate ion oxidation, with the poisoning effect of polysulfide ion being more pronounced in the potential range of -0.3 to $-0.2 \mathrm{~V} / \mathrm{SCE}$. The time constants for L-ascorbate ion oxidation in the absence and presence of polysulfide were, $10^{-3}$ to $1 \times 10^{-2} \mathrm{~s}$ and $1 \times 10^{-4}$ to $1 \times 10^{-2} \mathrm{~s}$, respectively depending on the potential used for the impedance analysis. Based on the cyclic voltammetry findings, a mechanism for L-ascorbate oxidation in the presence of polysulfide ions was proposed. Impedance calculations based on the kinetic analysis can account for the occurrence of a negative impedance in a potential region around $-0.2 \mathrm{~V} / \mathrm{SCE}$ in the Nyquist polts.
\end{abstract}

Key words: L-ascorbic acid; polysulfide; electrode poisoning; silver; electro-oxidation

CLC number: O643

Document code: A

Received 25 August 2011. Accepted 20 October 2011.

*Corresponding author.Tel: +98-21-66005718; Fax: +98-21-66012983; E-mail: kasmaee@mehr.sharif.edu

This work was supported by the office of vice chancellor of research of Sharif University of Technology.

English edition available online at Elsevier ScienceDirect (http://www.sciencedirect.com/science/journal/18722067).

L-ascorbic acid (L-AA) is a vital substance in the metabolism of living organisms and the determination of its concentration in aqueous solution is very important. Traditional procedures for this determination use enzymatic methods, titration with oxidizing agents, or HPLC analysis [1]. Recently, sensors have been developed for the electrochemical detection of L-AA $[2,3]$. L-AA has also been proposed as a potential environmentally friendly fuel for fuel cells [4]. The electro-catalytic activity of a number of transition metals [4,5] for L-AA electro-oxidation has been investigated, and silver was suggested as the best candidate in alkaline solutions [6]. In a cyclic voltammetry (CV) study, the oxidation of $0.25 \mathrm{~mol} / \mathrm{L} \mathrm{L-AA}$ in alkaline solution on polycrystalline $\mathrm{Ag}$ started at $-0.5 \mathrm{~V} / \mathrm{SCE}$ [6], which is $0.5 \mathrm{~V}$ more negative than in the reaction carried out in acidic media on electrodes of glassy carbon, Au, Pt-group metals or their alloys [4,5,7-9]

The electrochemistry of the sulfide anion on Ag has been studied in alkaline solution [10-17] but no definitive conclusion on the nature of the electrode processes was reached. The only electrochemical study on the polysulfide anion on $\mathrm{Ag}$ was carried out in a $\mathrm{Ag} / \mathrm{HS}_{4}{ }_{4}$ system in the potential range of -1.5 to $0.6 \mathrm{~V} / \mathrm{SSCE}$ (sodium saturated calomel electrode) [10]. This voltammetric study reported that the cathodic decomposition of $\mathrm{HS}_{4}^{-}$to $\mathrm{HS}^{-}$, which occurred in the vicinity of $-1.3 \mathrm{~V} / \mathrm{SSCE}$, was the source of sulfide for silver sulfide formation that occurred at -0.6 $\mathrm{V} / \mathrm{SSCE}$. $\mathrm{HS}_{4}{ }^{-}$decomposition to the sulfide anion was confirmed by holding the potential at $-1.3 \mathrm{~V} / \mathrm{SSCE}$ for $10 \mathrm{~s}$ before scanning anodically, which gave a dramatic increase in the peak height at $-0.6 \mathrm{~V} / \mathrm{SSCE}$ [10] that indicated that the $\mathrm{Ag} / \mathrm{HS}_{4}{ }^{-}$system was transformed to a $\mathrm{Ag} / \mathrm{HS}^{-}$system.

The $\mathrm{Ag}_{2} \mathrm{~S}$ film formation reaction was [14]

$$
2 \mathrm{Ag}+\mathrm{HS}^{-}+\mathrm{OH}^{-} \leftrightarrow \mathrm{Ag}_{2} \mathrm{~S}+\mathrm{H}_{2} \mathrm{O}+2 \mathrm{e}
$$

This reaction occurred at the reversible potential, $E_{r}$ (V/NHE) [14] of

$$
E_{r}=-0.684-0.0296 \log \left(\mathrm{HS}^{-}\right)-0.0296 \log \left(\mathrm{OH}^{-}\right)(2)
$$

In this study, $\mathrm{HS}^{-}$was produced by polysulfide decomposition in a reaction similar to that of tetra-sulfide decomposition in vicinity of $-1.3 \mathrm{~V} / \mathrm{SCE}[10]$ :

$$
\mathrm{HS}_{4}{ }^{-}+6 \mathrm{e}+3 \mathrm{H}_{2} \mathrm{O} \leftrightarrow 4 \mathrm{HS}^{-}+3 \mathrm{OH}^{-}
$$

In this study, the $\mathrm{OH}^{-}$and polysulfide concentrations were about $1 \times 10^{-2}$ and $1 \times 10^{-5} \mathrm{~mol} / \mathrm{L}$, respectively, and a very small fraction of polysulfide was transformed to $\mathrm{HS}^{-}$ during one anodic potential sweep in a cyclic voltammetry experiment. Assuming a $\mathrm{HS}^{-}$concentration of $1 \times 10^{-6}$ $\mathrm{mol} / \mathrm{L}, E_{r}$ would be $-0.69 \mathrm{~V} / \mathrm{SCE}$. This potential is much more positive than the potential of the redox peaks that we witnessed at -0.8 and $-1 \mathrm{~V} / \mathrm{SCE}$. So, the redox peaks were not due to silver sulfide formation but instead were due to the sulfide/sulfur redox pair, which has been reported $(-0.8$ 
and $-1.1 \mathrm{~V} / \mathrm{SCE}$ ) for the $\mathrm{Au} /$ sulfide system [18]. Also, contrary to the case of $\mathrm{Ag}_{2} \mathrm{~S}$ film formation [11], no dark (black) layer was witnessed during anodic polarization even after many hours of cycling.

The purpose of the present work was to investigate the kinetics of L-ascorbate ion oxidation on $\mathrm{Ag}$ in more detail and to study the poisoning effect of polysulfide ions on this reaction. Based on literature results [10], the potential range used in this study guarantees the presence of polysulfide and not sulfide anions in the solution.

\section{Experimental}

L-AA, $\mathrm{NaNO}_{3}$, and $\mathrm{NaOH}$ used were analytical grade from Merck. The sodium polysulfide was a general purpose reagent. The water used was first de-ionized. $\mathrm{NaNO}_{3}$ was added as the supporting electrolyte to the solution. Experiments were conducted in conventional three electrode cells with a Ag ribbon (99.99\% pure) with a geometric surface of $0.75 \mathrm{~cm}^{-2}$ as the working electrode. Its potential was measured against a commercial SCE (saturated calomel electrode). A Pt plate was the counter electrode. Electrochemical measurements, cyclic voltammetry, and impedance spectroscopy were performed using a Voltalab Model PGZ100 potentiostat/galvanostat. Impedance spectra were recorded in the frequency range of $25 \mathrm{kHz}$ to $100 \mathrm{mHz}$ and were fitted to the electric circuits by the Zview software.

\section{Results and discussion}

\subsection{L-ascorbate ion/ $\mathrm{NaOH}$ solution}

The electrochemical oxidation of L-ascorbate ion at various excess (compared to stoichiometry) concentrations of $\mathrm{NaOH}$ in the range of 0.01 to $0.6 \mathrm{~mol} / \mathrm{L}$ and in $0.5 \mathrm{~mol} / \mathrm{L}$ $\mathrm{NaNO}_{3}$ supporting electrolyte was studied. The cyclic voltammograms (CV's) are presented in Fig. 1.

The onset of reaction was shifted cathodically and the peak current increased asymptotically as the concentration of the excess alkali was increased. The onset potential shift was around $-0.06 \mathrm{~V}$ and the current increase was less than 2 -fold when the alkali concentration was increased 60 -fold. From the asymptotic dependence of the anodic peak current on hydroxide concentration, it is probable that $\mathrm{OH}^{-}$adsorption occurred and had a detrimental effect on the rate of oxidation at potentials more positive than $-0.2 \mathrm{~V} / \mathrm{SCE}$. The broad oxidation peak in the reverse scan at $-0.1 \mathrm{~V} / \mathrm{SCE}$ indicated that the hydroxide species adsorbed in the forward cycle desorbed in this potential region.

Figure 2 shows the dependence of the CV curves on the concentration of the L-ascorbate ion. An increase of peak current and its dramatic shift to higher potentials were ob-

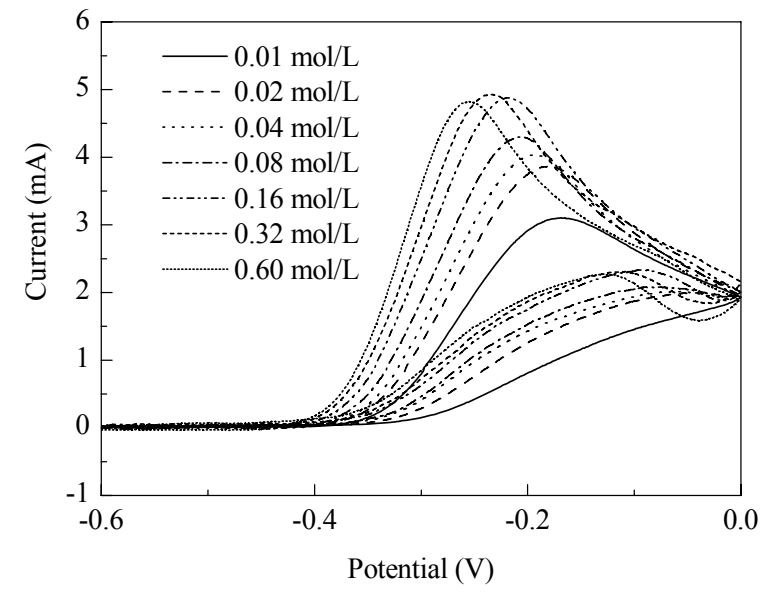

Fig. 1. Cyclic voltammograms recorded in solutions containing 0.5 $\mathrm{mol} / \mathrm{L} \mathrm{NaNO}_{3}+0.02 \mathrm{~mol} / \mathrm{L} \mathrm{Na} \mathrm{Na}_{2} \mathrm{AaOH}$ with different concentrations. $v=0.05 \mathrm{~V} / \mathrm{s}$.

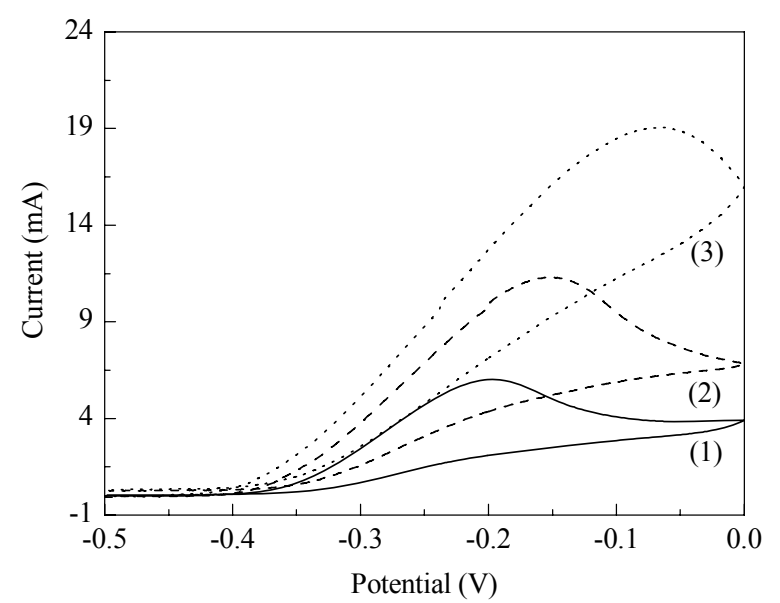

Fig. 2. Cyclic voltammograms recorded in solutions containing 0.5 $\mathrm{mol} / \mathrm{L} \mathrm{NaNO}_{3}+0.06 \mathrm{~mol} / \mathrm{L} \mathrm{NaOH}+\mathrm{Na}_{2} \mathrm{~A}$ of concentrations of 0.02 $\mathrm{mol} / \mathrm{L}(1), 0.04 \mathrm{~mol} / \mathrm{L}(2)$, and $0.06 \mathrm{~mol} / \mathrm{L}(3) . v=0.05 \mathrm{~V} / \mathrm{s}$.

served.

From the hydroxide and L-ascorbate concentration dependences of the $\mathrm{CV}$ curves, the mechanism below can be put forward. This mechanism is in agreement with the L-ascorbic acid oxidation mechanism at $\mathrm{pH}$ of 8 and less [19-21].

$$
\begin{aligned}
\mathrm{OH}_{\mathrm{aq}}^{-} & \leftrightarrow \mathrm{OH}_{\mathrm{ads}}^{-} & & \\
\mathrm{AH}_{\mathrm{aq}}^{-}+\mathrm{OH}_{\mathrm{ads}}^{-} & \rightarrow \mathrm{D}^{-}+\mathrm{H}_{2} \mathrm{O}+\mathrm{e} & & \text { slow } \\
\mathrm{D}^{-} & \rightarrow \mathrm{D}+\mathrm{e} & & \text { fast }
\end{aligned}
$$

$\mathrm{D}^{-}$and $\mathrm{D}$ are the intermediate and final products of the oxidation, respectively. $\mathrm{D}$ is accepted to be dehydroascorbic acid [20,21]. The $\mathrm{pH}$ range of this study, 12 to $13.8, \mathrm{p} K_{\mathrm{a} 1}$ and $\mathrm{p} K_{\mathrm{a} 2}$ for L-AA are 4.10 and 11.79 , respectively [22]. So, at $\mathrm{pH}=12$, the ratio of the $\mathrm{L}$-ascorbate di-anion to L-ascorbate anion species in the solution was 60/40. At $\mathrm{pH}$ values higher than 13.5 , less than $2 \%$ of $\mathrm{L}-\mathrm{AA}$ was in the form of the L-ascorbate ion and the L-ascorbate di-anion 


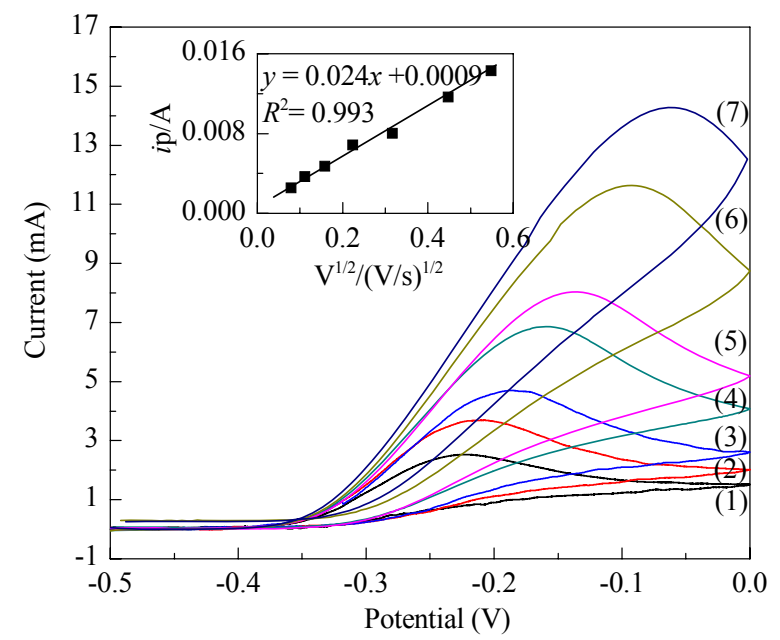

Fig. 3. Cyclic voltammograms recorded with a solution of $0.5 \mathrm{~mol} / \mathrm{L}$ $\mathrm{NaNO}_{3}+0.02 \mathrm{~mol} / \mathrm{L} \mathrm{Na} \mathrm{A}_{2} \mathrm{~A}+0.01 \mathrm{~mol} / \mathrm{L} \mathrm{NaOH}$ at various potential sweep rates. The inset shows peak current vs square root of the potential scan rate. (1) $6.25 \mathrm{mV} / \mathrm{s}$; (2) $12.5 \mathrm{mV} / \mathrm{s}$; (3) $25 \mathrm{mV} / \mathrm{s}$; (4) $50 \mathrm{mV} / \mathrm{s}$; (5) $100 \mathrm{mV} / \mathrm{s}$; (6) $200 \mathrm{mV} / \mathrm{s}$; (7) $300 \mathrm{mV} / \mathrm{s}$.

was the main species. $\mathrm{OH}^{-}$is not a reactant in the course of L-ascorbate di-anion oxidation and adsorbed $\mathrm{OH}^{-}$only inhibits L-ascorbate di-anion oxidation. Figure 3 shows the potential scan rate dependency of the voltammograms. As shown in the inset, at low $\mathrm{OH}^{-}$concentrations, there was a linear relationship between the peak current and square root of the scan rate, so the process was diffusion controlled.

Figure 4 shows the results of impedance measurements

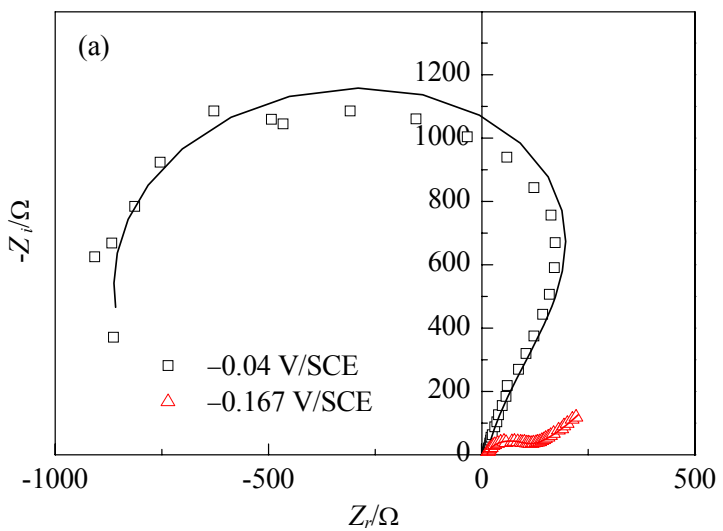

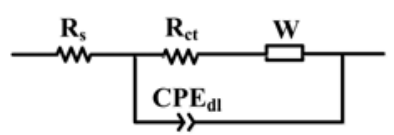

(a)

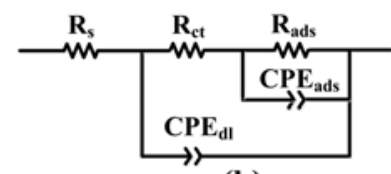

(b)
Fig. 5. Electric circuits employed to fit the Nyquist plots in Fig. 4.

recorded at various concentrations of $\mathrm{NaOH}$ in the presence of $0.5 \mathrm{~mol} / \mathrm{L} \mathrm{NaNO}_{3}$ when the ascorbate concentration was kept at $0.02 \mathrm{~mol} / \mathrm{L}$.

The spectra in Fig. 4 were fitted to circuits (a) and (b) shown in Fig. 5. The equivalent circuit parameters are summarized in Tables 1 and 2 .

$R_{\mathrm{s}}, R_{\mathrm{ct}}$, and $R_{\mathrm{ads}}$ are the solution, charge transfer, and adsorption resistances, respectively. $W$ is the Warburg element and $\mathrm{CPE}_{\mathrm{dl}}$ and $\mathrm{CPE}_{\mathrm{ads}}$ are constant phase elements that represent double layer and adsorption capacitances, respectively. While at the potentials corresponding to the ascending part of the voltammograms of 0.02 and $0.16 \mathrm{~mol} / \mathrm{L}$ $\mathrm{NaOH}$ in Fig. 1 the process quickly became diffusion controlled as manifested in the Nyquist plots by the straight lines in the low frequency end of the spectra, at the potentials corresponding to the descending parts of the cyclic voltammograms of 0.02 and $0.16 \mathrm{~mol} / \mathrm{L} \mathrm{NaOH}$, semicircles terminating in the fourth quarter (negative resistance side) of the Cole-Cole plots were observed at both low (0.02 $\mathrm{mol} / \mathrm{L})$ and high $(0.16 \mathrm{~mol} / \mathrm{L})$ concentrations of the alkali. The potential where this interesting pattern was observed corresponded to the rising part of the voltammogram in the

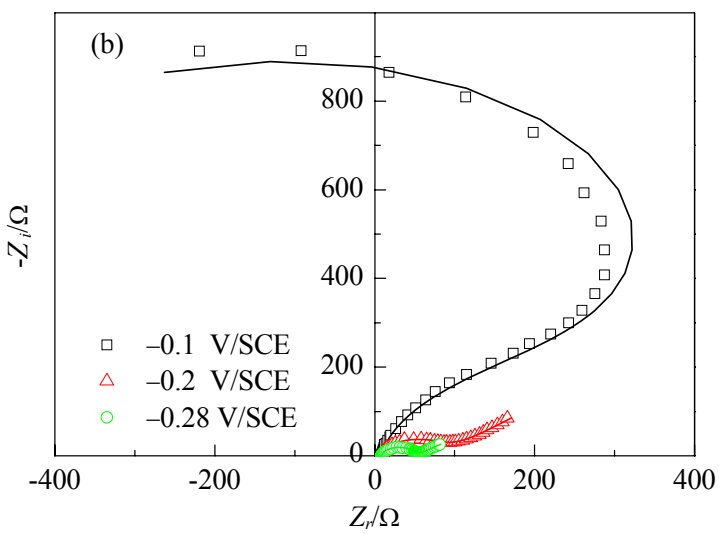

Fig. 4. Nyquist plots from a solution of $0.5 \mathrm{~mol} / \mathrm{L} \mathrm{NaNO}_{3}+0.02 \mathrm{~mol} / \mathrm{L} \mathrm{Na} 2 \mathrm{~A}+0.02 \mathrm{~mol} / \mathrm{L} \mathrm{NaOH}$ recorded at potentials of $-0.167 \mathrm{~V} / \mathrm{SCE}$ and -0.04 $\mathrm{V} / \mathrm{SCE}$ (a) and from a solution of $0.5 \mathrm{~mol} / \mathrm{L} \mathrm{NaNO}{ }_{3}+0.02 \mathrm{~mol} / \mathrm{L} \mathrm{Na} 2 \mathrm{~A}+0.16 \mathrm{~mol} / \mathrm{L} \mathrm{NaOH}$ recorded at potentials of $-0.28 \mathrm{~V} / \mathrm{SCE},-0.2 \mathrm{~V} / \mathrm{SCE}$, and $-0.1 \mathrm{~V} / \mathrm{SCE}(\mathrm{b})$.

Table 1 Equivalent circuit elements obtained by fitting the experimental results in Fig. 4(a) and relative errors in brackets

\begin{tabular}{|c|c|c|c|c|c|c|c|c|c|}
\hline$E /(\mathrm{V} / \mathrm{SCE})$ & $R_{\mathrm{S}} / \Omega$ & $R_{\mathrm{ct}} / \Omega$ & $R_{\mathrm{ads}} / \Omega$ & $C_{\mathrm{dl}} \times 10^{5} /\left(\mathrm{s}^{\mathrm{n}} / \Omega\right)$ & $n_{\mathrm{dl}}$ & $C_{\text {ads }} \times 10^{4} /\left(\mathrm{s}^{\mathrm{n}} / \Omega\right)$ & $n_{\mathrm{ads}}$ & $W /\left(\Omega / \mathrm{s}^{1 / 2}\right)$ & $n_{\mathrm{w}}$ \\
\hline \multirow[t]{2}{*}{-0.167} & 12.85 & 95.45 & - & 5.90 & 0.90 & - & - & 159.53 & 0.50 \\
\hline & $(0.44 \%)$ & $(2.15 \%)$ & - & $(0.70 \%)$ & $(0.59 \%)$ & - & - & $(0.31 \%)$ & $(1.89 \%)$ \\
\hline \multirow[t]{2}{*}{-0.04} & 13.03 & 1037.00 & -1693.0 & 7.56 & 0.91 & 1.89 & 0.53 & - & - \\
\hline & $(0.74 \%)$ & $(1.29 \%)$ & $(1.87 \%)$ & $(0.95 \%)$ & $(0.81 \%)$ & $(0.81 \%)$ & $(5.99 \%)$ & - & - \\
\hline
\end{tabular}


Table 2 Equivalent circuit elements obtained by fitting the experimental results in Fig. 4(b) and relative errors in brackets

\begin{tabular}{|c|c|c|c|c|c|c|c|c|c|}
\hline$E /(\mathrm{V} / \mathrm{SCE})$ & $R_{\mathrm{S}} / \Omega$ & $R_{\mathrm{ct}} / \Omega$ & $R_{\mathrm{ads}} / \Omega$ & $C_{\mathrm{dl}} \times 10^{5} /\left(\mathrm{s}^{\mathrm{n}} / \Omega\right)$ & $n_{\mathrm{dl}}$ & $C_{\text {ads }} \times 10^{4} /\left(\mathrm{s}^{\mathrm{n}} / \Omega\right)$ & $n_{\text {ads }}$ & $W /\left(\Omega / \mathrm{s}^{1 / 2}\right)$ & $n_{\mathrm{w}}$ \\
\hline \multirow[t]{2}{*}{-0.28} & 8.58 & 42.51 & - & 6.24 & 0.91 & - & - & 29.99 & 0.46 \\
\hline & $(0.50 \%)$ & $(0.86 \%)$ & - & $(0.75 \%)$ & $(0.53 \%)$ & - & - & $(1.32 \%)$ & $(0.92 \%)$ \\
\hline \multirow[t]{2}{*}{-0.2} & 8.56 & 75.61 & - & 7.53 & 0.91 & - & - & 132.69 & 0.52 \\
\hline & $(0.47 \%)$ & $(1.66 \%)$ & - & $(0.64 \%)$ & $(0.53 \%)$ & - & - & $(1.15 \%)$ & $(1.22 \%)$ \\
\hline \multirow[t]{2}{*}{-0.1} & 8.59 & 315.20 & -728.00 & 9.19 & 0.92 & 1.14 & 0.62 & - & - \\
\hline & $(0.76 \%)$ & $(5.26 \%)$ & $(0.80 \%)$ & $(0.87 \%)$ & $(0.20 \%)$ & $(1.03 \%)$ & $(3.34 \%)$ & - & - \\
\hline
\end{tabular}

Table 3 Equivalent circuit elements obtained by fitting the experimental results in Fig. 8 and relative errors

\begin{tabular}{|c|c|c|c|c|c|c|c|c|c|}
\hline$E /(\mathrm{V} / \mathrm{SCE})$ & $R_{\mathrm{S}} / \Omega$ & $R_{\mathrm{ct}} / \Omega$ & $R_{\mathrm{ads}} / \Omega$ & $C_{\mathrm{dl}} \times 10^{5} /\left(\mathrm{s}^{\mathrm{n}} / \Omega\right)$ & $n_{\mathrm{dl}}$ & $C_{\text {ads }} \times 10^{4} /\left(\mathrm{s}^{\mathrm{n}} / \Omega\right)$ & $n_{\mathrm{ads}}$ & $W /\left(\Omega / \mathrm{s}^{1 / 2}\right)$ & $n_{\mathrm{w}}$ \\
\hline \multirow{2}{*}{-0.4} & 9.35 & 115.34 & - & 48.07 & 0.83 & - & - & - & - \\
\hline & $(0.21 \%)$ & $(1.02 \%)$ & - & $(1.25 \%)$ & $(0.48 \%)$ & - & - & - & - \\
\hline \multirow[t]{2}{*}{-0.3} & 9.83 & 60.05 & - & 42.93 & 0.79 & - & - & 12.7 & 0.49 \\
\hline & $(0.61 \%)$ & $(1.35 \%)$ & - & $(1.01 \%)$ & $(0.81 \%)$ & - & - & $(4.52 \%)$ & $(4.95 \%)$ \\
\hline \multirow[t]{2}{*}{-0.24} & 9.72 & 5.44 & -141.40 & 4.20 & & 5.40 & 0.77 & - & - \\
\hline & $(0.52 \%)$ & $(2.61 \%)$ & $(0.43 \%)$ & $(2.03 \%)$ & 1 & $(0.79 \%)$ & $(0.54 \%)$ & - & - \\
\hline \multirow[t]{2}{*}{-0.167} & 9.41 & 92.93 & - & 38.87 & 0.76 & - & - & 10.24 & 0.58 \\
\hline & $(0.41 \%)$ & $(0.65 \%)$ & - & $(0.52 \%)$ & $(0.40 \%)$ & - & - & $(4.21 \%)$ & $(4.14 \%)$ \\
\hline
\end{tabular}

reverse (cathodic) half cycle. In this region, desorption of $\mathrm{OH}^{-}$species creates sites for the oxidation of $\mathrm{AH}^{-}$species, hence, the oxidation current increase. The decrease in the current in the anodic sweep was not only due to mass transfer limitation, and there was contribution from "poisoning by $\mathrm{OH}^{-}$species". Based on Table 1, the time constant for the charge transfer reaction $\left(\tau_{\mathrm{ct}}=R_{\mathrm{ct}} C_{\mathrm{dl}}\right)$ was calculated to be $5.6 \times 10^{-3}$ and $7.8 \times 10^{-2} \mathrm{~s}$ at -0.167 and $-0.04 \mathrm{~V} / \mathrm{SCE}$, respectively. So the rate of charge transfer was increased 10 fold as hydroxide ion adsorption inhibited the oxidation reaction. The same pattern was observed at higher $\mathrm{OH}^{-}$ concentrations as well. According to the $R_{\mathrm{ct}}$ and $C_{\mathrm{dl}}$ values in Table 2, $\tau_{\text {ct }}$ values were $2.7 \times 10^{-3}, 5.7 \times 10^{-3}$, and $2.9 \times$ $10^{-2} \mathrm{~s}$ at $-0.28,-0.2$, and $-0.1 \mathrm{~V} / \mathrm{SCE}$, respectively. At -0.2 $\mathrm{V} / \mathrm{SCE}$, due to the mass transfer limitation, the rate constant of the oxidation process was about half the value of the rate constant at $-0.28 \mathrm{~V} / \mathrm{SCE}$. At $-0.1 \mathrm{~V} / \mathrm{SCE}$ where the adsorption of hydroxide ion diminished the charge transfer rate, the rate constant was again 10 fold smaller than that at $-0.28 \mathrm{~V} / \mathrm{SCE}$.

\subsection{L-ascorbate ion/( $\mathrm{NaOH}+$ polysulfide ion)}

The polysulfide used in this work was $\mathrm{HS}_{x}^{-}(x=11)$, with the $x$ obtained by density measurement. On a Ag electrode, this species shows redox peaks in the range of -0.3 to -0.1 V/SCE with no apparent damage to the Ag. The conditioning of the $\mathrm{Ag}$ in a solution of $5 \times 10^{-3} \mathrm{~mol} / \mathrm{L}$ polysulfide and $0.5 \mathrm{~mol} / \mathrm{L} \mathrm{NaOH}$ at $-1.2 \mathrm{~V} / \mathrm{SCE}$ prior to recording a cyclic voltammogram generates a pair of redox peaks at -0.8 and $-0.95 \mathrm{~V} / \mathrm{SCE}$, which have been assigned to $\mathrm{HS}^{-} / \mathrm{S}$ in the literature [10,16-18], and increased intensity was observed on increasing the conditioning time. These results are in agreement with the findings for the $\mathrm{Ag} / \mathrm{HS}_{4}{ }^{-}$system described in the introduction. So, the irreversible reduction of polysulfide prevailed at the conditioning potential. We have avoided this range of potential to make sure that the sulfur remained in the polysulfide form. Figure 6 presents the effect of polysulfide addition at various concentrations on the electro-oxidation of L-ascorbate ion at low and high concentrations of the alkali.

In both cases, a moderate fall in reactivity at around -0.3 to $-0.2 \mathrm{~V} / \mathrm{SCE}$ was accompanied by new activity emerging in the region of -0.2 to $-0.1 \mathrm{~V} / \mathrm{SCE}$ with the effects being more pronounced at low alkali concentration. The rise of the anodic current in the potential region of -0.2 to $0 \mathrm{~V} / \mathrm{SCE}$ has neither been observed in the absence of the L-ascorbate ion nor in presence of sulfide ion concentrations up to $1 \times$ $10^{-3} \mathrm{~mol} / \mathrm{L}$. It therefore was probably due to L-ascorbate ion oxidation on polysulfide covered sites. Interrupting of the anodic sweep at $-0.2 \mathrm{~V} / \mathrm{SCE}$ for $30 \mathrm{~s}$ or more has a detrimental effect on the intensity of the following rising current. So, the further oxidation of the oxidation products can be dismissed. Also, the activity that resulted behaved more regularly, and a strong anodic peak appeared in the cathodic half cycle under the regular peak from ascorbate ion oxidation. Figure 7 show the effects of $\mathrm{L}$-ascorbate ion and $\mathrm{NaOH}$ concentrations at constant polysulfide $\left(1 \times 10^{-4} \mathrm{~mol} / \mathrm{L}\right)$ concentration.

In Fig. 7(a), a similar behavior as in the absence of polysulfide (Fig. 2) was observed with increasing L-ascorbate concentration, and the intensity of both peaks increased monotonically. Changes in hydroxide ion concentration however affected only the first anodic peak in Fig. 7(b), its 

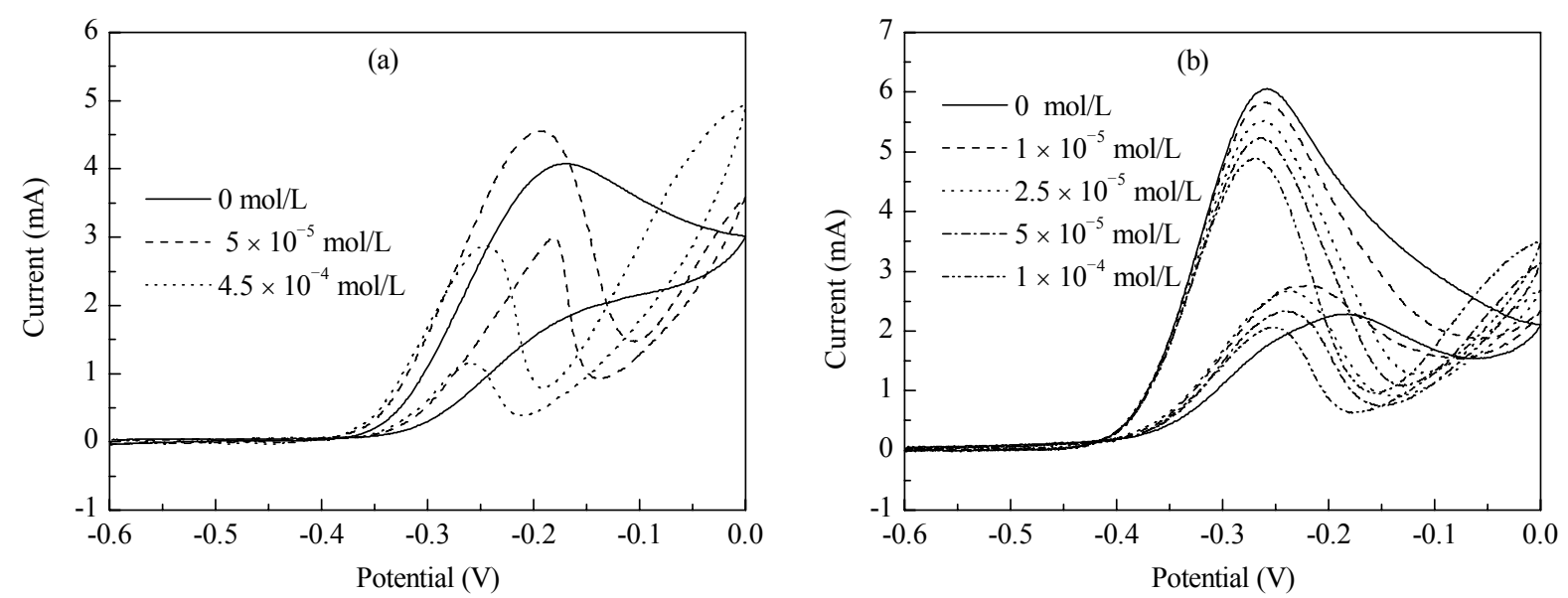

Fig. 6. Cyclic voltammograms recorded in solutions of $0.5 \mathrm{~mol} / \mathrm{L} \mathrm{NaNO}+0.02 \mathrm{~mol} / \mathrm{L} \mathrm{Na}_{2} \mathrm{~A}+0.01 \mathrm{~mol} / \mathrm{L} \mathrm{NaOH}+$ polysulfide with different concentrations (a) and $0.02 \mathrm{~mol} / \mathrm{L} \mathrm{Na}_{2} \mathrm{~A}+1 \mathrm{~mol} / \mathrm{L} \mathrm{NaOH}+$ polysulfide with different concentrations (b). $v=0.05 \mathrm{~V} / \mathrm{s}$.

effect was less than that of the ascorbate concentration, and the reactivity at more anodic potentials was negligibly affected by the alkali concentration. There appeared to be no mechanism change at the lower oxidation potential. Apparently the polysulfide species simply occupied the sites used for L-ascorbate oxidation at low potentials while creating sites on which oxidation can proceed at higher potentials. The anodic peak in the cathodic half cycle was attributed to renewed oxidation as the reductive desorption of polysulfide occurred. From the CV results, a kinetic model based on adsorbed polysulfide (undergoing charge transfer) and adsorbed hydroxide is

$$
\begin{gathered}
\mathrm{HS}_{x(\mathrm{aq})}^{-} \stackrel{k_{f 4}}{\stackrel{k_{b 4}}{\longrightarrow}} \mathrm{HS}_{x(\mathrm{ads})}+\mathrm{e} \\
\mathrm{OH}_{\mathrm{aq}}^{-} \stackrel{k_{f 5}}{\stackrel{k_{b 5}}{\longrightarrow}} \mathrm{OH}_{\mathrm{ads}}^{-} \\
\mathrm{AH}_{\mathrm{aq}}^{-}+\mathrm{OH}_{\mathrm{ads}}^{-} \stackrel{\stackrel{k_{6}}{\longrightarrow} \mathrm{D}^{-}+\mathrm{H}_{2} \mathrm{O}+\text { e slow }}{\mathrm{D}^{-} \rightarrow \mathrm{D}+\mathrm{e} \text { fast }}
\end{gathered}
$$

This mechanism is in agreement with the literature
[19-21] and supported by our CV findings. To further verify this, impedance measurements were carried out. Figure 8 presents the Nyquist plots recorded at the various potentials of the cyclic voltammograms of $4.5 \times 10^{-4} \mathrm{~mol} / \mathrm{L} \mathrm{Na}_{2} \mathrm{~A}$ in Fig. 6(a).

These plots were fitted to the circuits in Fig. 9. The circuit parameters are presented in Table 3.

Figure 8 shows a pure charge transfer at the onset of oxidation (single squashed semi-circle in Fig. 8(a)), charge transfer-mass transfer (semi-circle terminating into a Warburg line in Figs. 8(b) and (d)) and two overlapping semi-circles terminating in the fourth quadrant in Fig. 8(c) (negative resistance). The last pattern occurred along the descending part (almost at the peak) of the voltammograms, which coincided with the ascending part of the anodic currents in the cathodic half cycle. At more anodic potentials and along the second rising oxidation process, pure charge transfer and charge transfer-mass transfer processes were again dominant (Fig. 8(d)). Based on the fitted circuit pa-
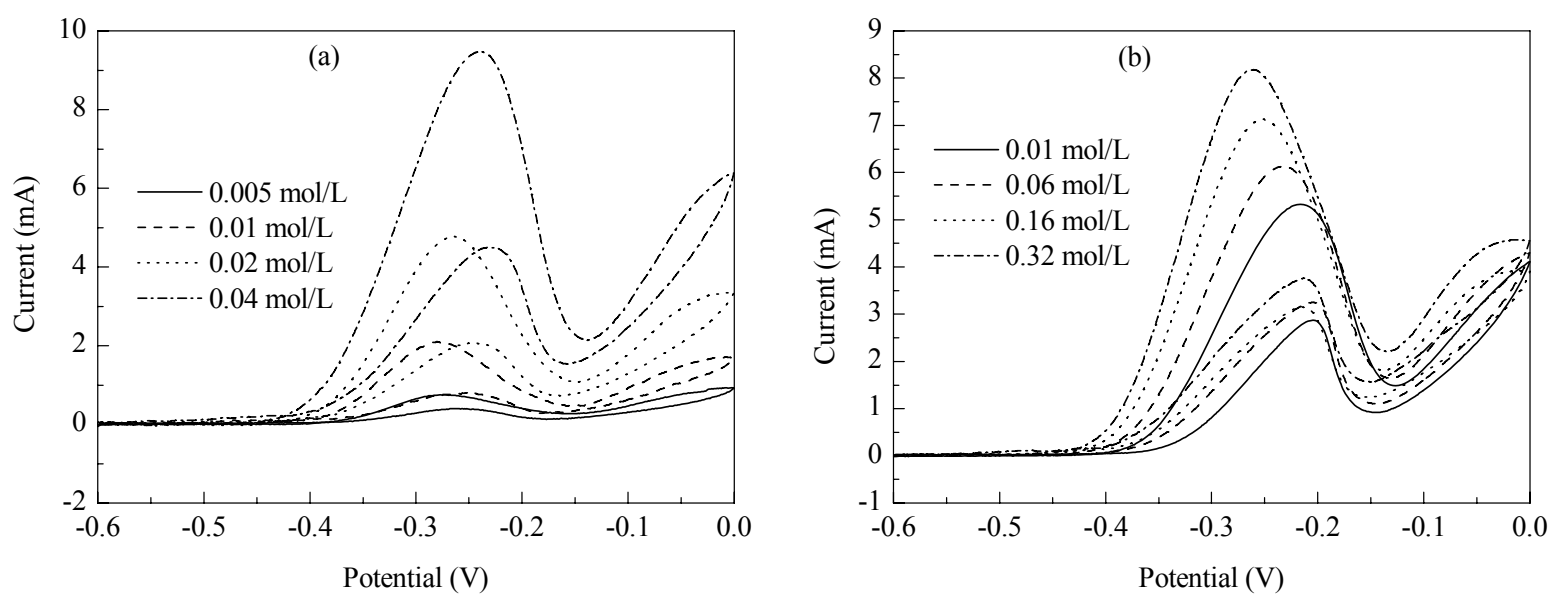

Fig. 7. Cyclic voltammograms recorded in different solutions. (a) $1 \mathrm{~mol} / \mathrm{L} \mathrm{NaOH}+10^{-4} \mathrm{~mol} / \mathrm{L}$ polysulfide $+\mathrm{Na}_{2} \mathrm{~A}$ with different concentrations; (b) $0.5 \mathrm{~mol} / \mathrm{L} \mathrm{NaNO}_{3}+10^{-4} \mathrm{~mol} / \mathrm{L}$ polysulfide $+\mathrm{Na}_{2} \mathrm{~A}$ with different concentrations. $v=0.05 \mathrm{~V} / \mathrm{s}$. 


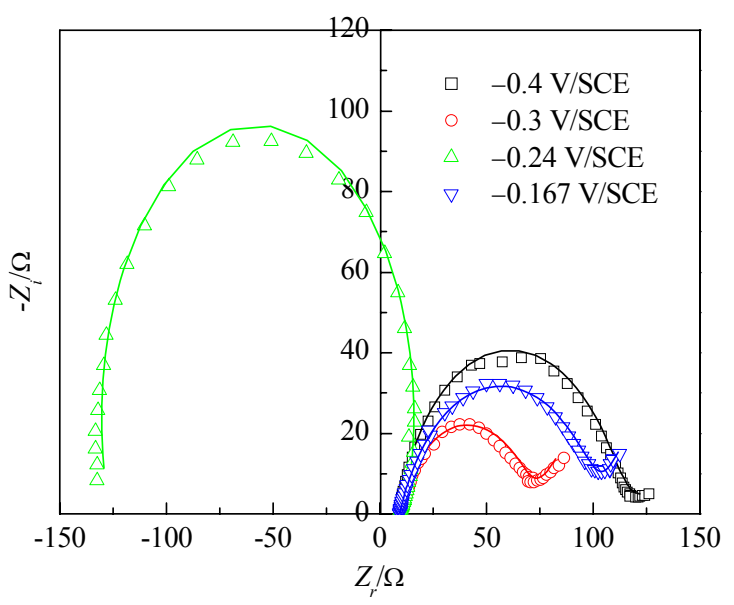

Fig. 8. Nyquist plots from a solution of $0.5 \mathrm{~mol} / \mathrm{L} \mathrm{NaNO}_{3}+0.01$ $\mathrm{mol} / \mathrm{L} \mathrm{NaOH}+0.02 \mathrm{~mol} / \mathrm{L} \mathrm{Na} 2 \mathrm{~A}+4.5 \times 10^{-4} \mathrm{~mol} / \mathrm{L}$ polysulfide recorded at $-0.4 \mathrm{~V} / \mathrm{SCE},-0.3 \mathrm{~V} / \mathrm{SCE},-0.24 \mathrm{~V} / \mathrm{SCE}$, and $-0.167 \mathrm{~V} / \mathrm{SCE}$.

rameters in Table 3 , at -0.4 and $-0.3 \mathrm{~V} / \mathrm{SCE}$, the time constants of the charge transfer process were $5.5 \times 10^{-2}$ and 2.5 $\times 10^{-2} \mathrm{~s}$. So, as expected, at $-0.4 \mathrm{~V} / \mathrm{SCE}$ where the oxidation process has just started, the charge transfer rate was lower than that at $-0.3 \mathrm{~V} / \mathrm{SCE}$. At $-0.24 \mathrm{~V} / \mathrm{SCE}$, both $R_{\mathrm{ct}}$ and $C_{\mathrm{dl}}$, and consequently $\tau_{\mathrm{ct}}$ (which was $2.28 \times 10^{-4} \mathrm{~s}$ ) were exceptionally smaller than at the other potentials. At -0.167 $\mathrm{V} / \mathrm{SCE}, \tau_{\mathrm{ct}}$ was $3.6 \times 10^{-2} \mathrm{~s}$ and in the same range as those at -0.4 and $-0.3 \mathrm{~V} / \mathrm{SCE}$.

Nyquist plots recorded in solutions of $0.5 \mathrm{~mol} / \mathrm{L} \mathrm{NaNO}_{3}$, $0.02 \mathrm{~mol} / \mathrm{L} \mathrm{L}$-ascorbate, $10^{-4} \mathrm{~mol} / \mathrm{L}$ polysulfide, and various concentrations of hydroxide are presented in Fig. 10.

The equivalent circuit parameters derived by fitting the impedance data in Fig. 10 to the equivalent circuits of Figs. 9(b) and 9(c) are presented in Tables 4 and 5, respectively. The voltammetry studies suggested that the polysulfide ef-
Table 5 Equivalent circuit elements obtained by fitting the experimental results in Fig. 10(B) and relative errors

\begin{tabular}{cccccc}
\hline $\begin{array}{c}\text { OH concentra- } \\
\text { tion (mol/L) }\end{array}$ & $R_{\mathrm{s}} / \Omega$ & $R_{\mathrm{ct}} / \Omega$ & $\begin{array}{c}C_{\mathrm{dl}} \times 10^{5} \\
\left(\mathrm{~s}^{\mathrm{n}} / \Omega\right)\end{array}$ & $n_{\mathrm{dl}}$ & $W /\left(\Omega / \mathrm{s}^{1 / 2}\right)$ \\
\hline 0.06 & 6.73 & 49.05 & 22.26 & 0.84 & 51.49 \\
& $(0.50 \%)$ & $(1.20 \%)$ & $(0.67 \%)$ & $(0.54 \%)$ & $(0.85 \%)$ \\
0.16 & 5.57 & 54.08 & 32.38 & 0.82 & 51.55 \\
& $(0.60 \%)$ & $(1.42 \%)$ & $(0.79 \%)$ & $(0.62 \%)$ & $(1.01 \%)$ \\
0.32 & 4.57 & 44.94 & 35.31 & 0.83 & 45.05 \\
& $(0.51 \%)$ & $(1.33 \%)$ & $(0.61 \%)$ & $(0.51 \%)$ & $(1.35 \%)$ \\
\hline
\end{tabular}

fect was less at higher hydroxide concentrations. The trend shown by the Nyquist plots recorded at $-0.2 \mathrm{~V} / \mathrm{SCE}$ (Fig. 10(a)) was in agreement with this finding. As the hydroxide concentration increased, its adsorption overwhelmed polysulfide adsorption and diminished the poisoning effects of polysulfide, and therefore the overall $Z_{r}$ became less negative. The Nyquist plots presented in Fig. 10(b) were in accord with the voltammograms in Fig. 7 (b) at $-0.1 \mathrm{~V} / \mathrm{SCE}$, which was in the potential region of the second ascending part in the anodic potential sweep. The hydroxide ion did not play a significant role in the oxidation reaction, the $\mathrm{Ny}$ quist plots were fairly similar to each other, and the charge transfer-mass transfer behavior expected at this potential were observed. The resumption of L-ascorbate ion oxidation after passing the first oxidation peak in Fig. 7 supported the argument that the fall in current was not entirely due to mass transfer limitation, and was probably mostly due to the competitive adsorption of $\mathrm{HS}_{x}{ }^{-}$and, to a less extent, $\mathrm{OH}^{-}$. From the $C_{\mathrm{dl}}$ and $R_{\mathrm{ct}}$ values in Table $4, \tau_{c t}$ values were calculated to be $3.3 \times 10^{-4}, 3.5 \times 10^{-4}, 4.5 \times 10^{-4}$, and $4.3 \times$ $10^{-4} \mathrm{~s}$ at $-0.2 \mathrm{~V} / \mathrm{SCE}$ for solutions of $0.01,0.06,0.16$, and $0.32 \mathrm{~mol} / \mathrm{L}$ hydroxide, respectively. The rate of charge transfer was fast and was not affected by the hydroxide ion

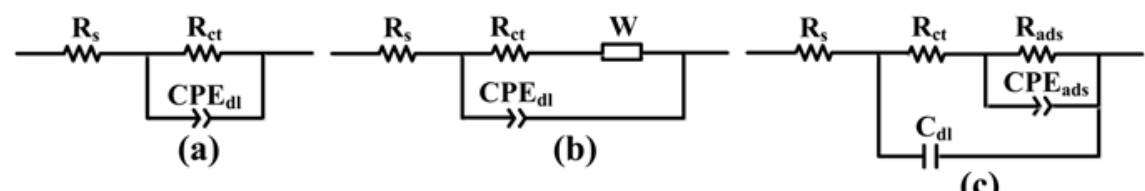

Fig. 9. Electric circuits employed to fit the Nyquist plots in Figs 8 and 10.

Table 4 Equivalent circuit elements obtained by fitting the experimental results in Fig. 10(a) and relative errors

\begin{tabular}{|c|c|c|c|c|c|c|}
\hline OH concentration $(\mathrm{mol} / \mathrm{L})$ & $R_{\mathrm{S}} / \Omega$ & $R_{\mathrm{ct}} / \Omega$ & $R_{\mathrm{ads}} / \Omega$ & $C_{\mathrm{dl}} \times 10^{5}(\mathrm{~F})$ & $C_{\text {ads }} \times 10^{3}\left(\mathrm{~s}^{\mathrm{n}} / \Omega\right)$ & $n_{\text {ads }}$ \\
\hline \multirow[t]{2}{*}{0.01} & 7.79 & 6.51 & -95.14 & 5.03 & 1.34 & 0.60 \\
\hline & $(0.42 \%)$ & $(2.35 \%)$ & $(0.43 \%)$ & $(1.33 \%)$ & $(0.48 \%)$ & $(0.95 \%)$ \\
\hline \multirow[t]{2}{*}{0.06} & 7.01 & 6.67 & -86.94 & 5.22 & 1.11 & 0.63 \\
\hline & $(0.53 \%)$ & $(2.32 \%)$ & $(0.45 \%)$ & $(1.23 \%)$ & $(0.55 \%)$ & $(0.93 \%)$ \\
\hline \multirow[t]{2}{*}{0.16} & 5.79 & 6.32 & -77.41 & 7.15 & 1.15 & 0.66 \\
\hline & $(0.68 \%)$ & $(3.34 \%)$ & $(0.69 \%)$ & $(1.44 \%)$ & $(0.90 \%)$ & $(1.32 \%)$ \\
\hline \multirow[t]{2}{*}{0.32} & 4.76 & 6.14 & -60.10 & 6.97 & 2.11 & 0.57 \\
\hline & $(0.69 \%)$ & $(4.41 \%)$ & $(0.67 \%)$ & $(1.94 \%)$ & $(0.68 \%)$ & $(1.65 \%)$ \\
\hline
\end{tabular}



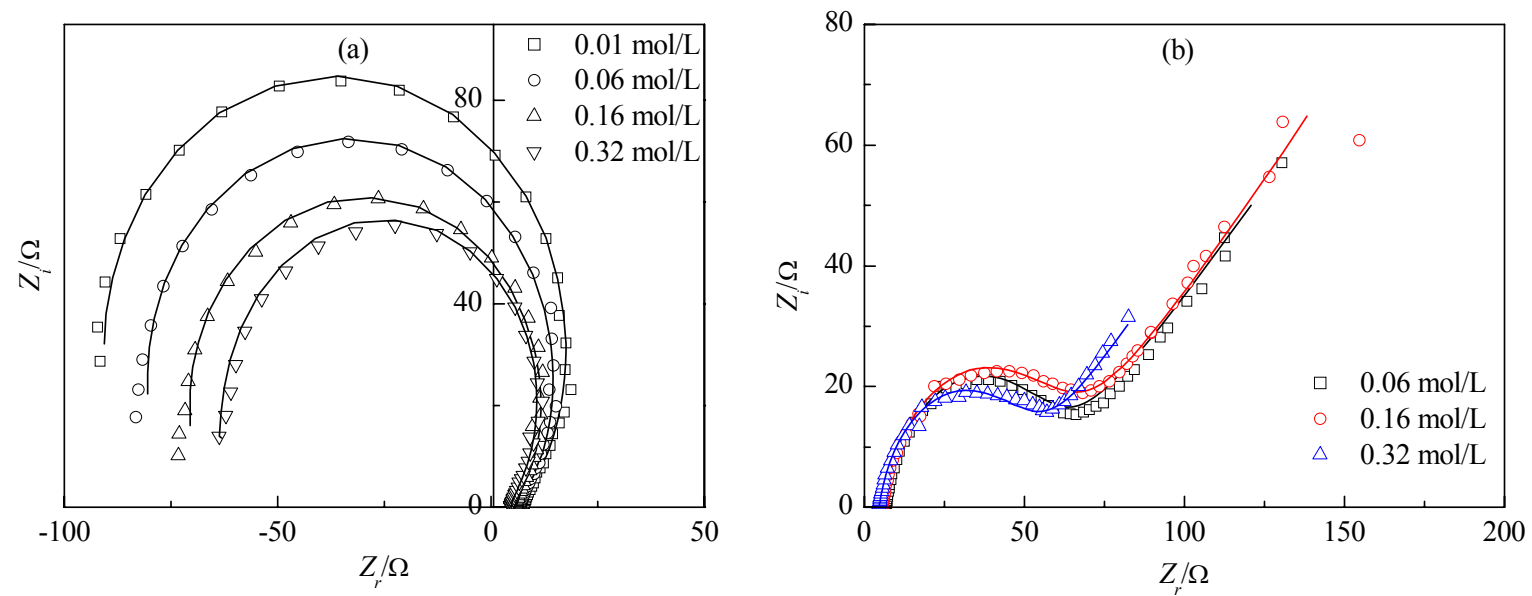

Fig. 10. Nyquist plots in solutions of $0.5 \mathrm{~mol} / \mathrm{L} \mathrm{NaNO}_{3}+0.02 \mathrm{~mol} / \mathrm{L} \mathrm{Na} 2 \mathrm{~A}+10^{-4} \mathrm{~mol} / \mathrm{L}$ polysulfide $+\mathrm{NaOH}$ with different concentrations (a) and $0.5 \mathrm{~mol} / \mathrm{L} \mathrm{NaNO}_{3}+0.02 \mathrm{~mol} / \mathrm{L} \mathrm{Na}_{2} \mathrm{~A}+10^{-4} \mathrm{~mol} / \mathrm{L}$ polysulfide $+\mathrm{NaOH}$ with different concentrations (b).

\section{concentration.}

As can be seen in the voltammograms of Fig. 7(b), at $-0.2 \mathrm{~V} / \mathrm{SCE}$, the desorption of polysulfide and hydroxide ions shown by the anodic peak in the cathodic sweep provided more sites for L-ascorbate ion oxidation, and thus the rate of charge transfer was accelerated. The values of $\tau_{\mathrm{ct}}$ at $-0.1 \mathrm{~V} / \mathrm{SCE}$ were calculated for solutions containing 0.06 , 0.16 , and $0.32 \mathrm{~mol} / \mathrm{L}$ hydroxide ion, from the double layer capacitance and charge transfer resistance data in Table 5, to be $1.1 \times 10^{-2}, 1.8 \times 10^{-2}$, and $1.6 \times 10^{-2} \mathrm{~s}$, respectively. The time constant values confirmed the voltammetric finding (Fig. 7(b)) that at $-0.1 \mathrm{~V} / \mathrm{SCE}$, the rate of charge transfer was not influenced by the hydroxide species.

To clarify the effects of the reaction constituents on the kinetics at the potential domain where the negative resistance was observed, an impedance analysis based on the proposed mechanism (equations 4-7) was carried out. In the impedance measurement regime, $i=\tilde{i}+\bar{i}, \varphi=\tilde{\varphi}+\bar{\varphi}$, and $\theta=\tilde{\theta}+\bar{\theta}$, where overbar and tilde symbols are steady state and frequency dependent quantities, respectively. The frequency dependent quantities are generally expressed as $\tilde{X}=X_{0} \exp (j \omega t)$. The Faradic current $(i)$ was calculated from the rates of electron transfer in equations $4\left(i_{f 4}\right.$ and $\left.i_{b 4}\right)$ and $6\left(i_{6}\right)$.

$$
\begin{aligned}
& i=i_{f 4}-i_{b 4}+i_{6}=F \bar{k}_{f 4} C_{S}\left(1-\theta_{\mathrm{OH}}-\theta_{\mathrm{S}}\right) \\
& \exp (b \varphi)-F \bar{k}_{b 4} \theta_{S} \exp (-b \varphi)+ \\
& F \bar{k}_{6} C_{\mathrm{AH}} \theta_{\mathrm{OH}}\left(1-\theta_{\mathrm{OH}}-\theta_{\mathrm{S}}\right) \exp \left(b^{\prime} \varphi\right)
\end{aligned}
$$

where $b=\left(\frac{-\alpha F}{R T}\right), \quad-b=\left(\frac{(1-\alpha) F}{R T}\right)$, and $b^{\prime}=\left(\frac{-\alpha^{\prime} F}{R T}\right)$.

The S, OH, and AH subscripts represents polysulfide, hydroxide, and L-ascorbate ions, respectively. The other symbols have their usual meaning. The frequency dependent part of the current was calculated to be

$$
\begin{aligned}
& \tilde{i}=\left[b i_{f 4}+b i_{b 4}+b^{\prime} i_{6}\right] \tilde{\varphi}-\left[F \bar{k}_{f 4} C_{S} \exp (b \varphi)+\right. \\
& \left.F \bar{k}_{b 4} \exp (-b \varphi)+F \bar{k}_{6} C_{A H} \theta_{O H} \exp \left(b^{\prime} \varphi\right)\right] \tilde{\theta}_{S}
\end{aligned}
$$

Using $\Gamma$ as the maximum coverage attained by the polysulfide anion, the rate of change of the surface coverage is $F \Gamma \frac{d \theta_{\mathrm{S}}}{d t}=i_{f 4}-i_{b 4}$, and the alternate part of polysulfide surface coverage was obtained as:

$$
\tilde{\theta}_{S}=\frac{\left(b i_{f 4}+b i_{b 4}\right)}{F \Gamma j \omega+\left(F k_{f 4} C_{S} \exp (b \varphi)+F k_{b 4} \exp (-b \varphi)\right)} \tilde{\varphi}
$$

As hydroxide ion adsorption was not involved in any electron transfer process (equation 8 ), $\theta_{\mathrm{OH}}=\tilde{\theta}_{\mathrm{OH}}+\bar{\theta}_{\mathrm{OH}}$ is equal to $\frac{\bar{K}_{\mathrm{OH}} C_{\mathrm{OH}}}{1+\bar{K}_{\mathrm{OH}} C_{\mathrm{OH}}+\bar{K}_{\mathrm{S}} C_{\mathrm{S}} \exp (-F \varphi / R T)}$ where $\bar{K}_{\mathrm{S}}=\frac{\bar{k}_{f 4}}{\bar{k}_{b 4}}$ and $\bar{K}_{\mathrm{OH}}=\frac{\bar{k}_{f 5}}{\bar{k}_{b 5}}$. Since the polysulfide concentration was small, $\theta_{\mathrm{OH}}$ further simplifies to $\frac{\bar{K}_{\mathrm{OH}} C_{\mathrm{OH}}}{1+\bar{K}_{\mathrm{OH}} C_{\mathrm{OH}}}$, which is frequency independent.

The total impedance is $Z=Z_{i}+Z_{r}=\frac{\tilde{\varphi}}{\tilde{i}}=\frac{\Gamma j \omega+D}{A \Gamma j \omega+A D-B C}$ in which $A, B, C$ and $D$ are

$$
\begin{aligned}
& A=b i_{f 4}+b i_{b 4}+b^{\prime} i_{6}, \quad B=b i_{f 4}+b i_{b 4} \\
& C=F \bar{k}_{f 4} C_{\mathrm{S}} \exp (b \varphi)+F \bar{k}_{b 4} \exp (-b \varphi)+ \\
& F \bar{k}_{6} C_{\mathrm{AH}} \theta_{\mathrm{OH}} \exp \left(b^{\prime} \varphi\right) \\
& \quad D=F \bar{k}_{f 4} C_{\mathrm{S}} \exp (b \varphi)+F \bar{k}_{b 4} \exp (-b \varphi)(14)
\end{aligned}
$$

When $\omega \rightarrow 0, Z_{r}$ simplifies to $\frac{D}{b^{\prime} i_{6} D-E \theta_{\mathrm{OH}} \exp \left(b^{\prime} \varphi\right)}$.

Here $E=F b \bar{k}_{6} C_{\mathrm{AH}}$, and since all the above terms are positive, $Z_{r}$ attains negative value when 
$b^{\prime} i_{6} D<E \theta_{\mathrm{OH}} \exp \left(b^{\prime} \varphi\right) . \quad \theta_{\mathrm{OH}}=\bar{\theta}_{\mathrm{OH}}=\frac{\bar{K}_{\mathrm{OH}} C_{\mathrm{OH}}}{1+\bar{K}_{\mathrm{OH}} C_{\mathrm{OH}}}$, so

the increase of hydroxide concentration up to the surface saturation limit increases $\theta_{\mathrm{OH}}$, and consequently the negative impedance value decreases. This finding was confirmed by the values of $Z_{r}$ in Table 4 and Fig. 10(a).

\section{Conclusions}

The electro-oxidation of L-ascorbate on Ag in alkali solution takes place by a mechanism where hydroxide ion is both a reactant and an inhibitor. The introduction of polysulfide ions into the system affects the CV curves and the electro-oxidation process is governed by the competitive adsorption of hydroxide and polysulfide anions. The impedance measurements produced Nyquist plots that exhibited capacitive and negative resistances as well as a Warburg line, and can be accounted for by the proposed mechanism. In the presence of polysulfide ions, changes in the hydroxide ion concentration have a marginal inhibiting effect at around $-0.2 \mathrm{~V} / \mathrm{SCE}$ where the highest activities were obtained.

\section{References}

1 Kumar S A, Cheng H, Chen S. React Funct Polym, 2009, 69: 364

2 Chitravathi S, Kumara Swamy B E, Mamatha G P, Sherigara B S. J Mol Liq, 2011, 160: 193

3 Tian L, Chen L, Liu L, Lu N, Song W B, Xu H D. Sens Actuators $B$, 2006, 113: 150

4 Fujiwara N, Yasuda K, Ioroi T, Siroma Z, Miyazaki Y, Kobayashi T. Electrochem Solid-State Lett, 2003, 6(12): A257
5 Fujiwara N, Siroma Z, Ioroi T, Yasuda K. J Power Sources, 2007, 164: 457

6 Majari Kasmaee L, Gobal F. J Power Sources, 2010, 195: 165

7 Fujiwara N, Yamazaki S, Siroma Z, Ioroi T, Yasuda K. $J$ Power Sources, 2007, 167: 32

8 Uhm S, Choi J, Chung S T, Lee J. Electrochim Acta, 2007, 53: 1731

9 Fujiwara N, Yamazaki S, Siroma Z, Ioroi T, Yasuda K. Electrochem Commun, 2006, 8: 720

10 Power G P, Ritchie I M, Wylie M T. Electrochim Acta, 1981, 26: 1633

11 Shimizu K, Aoki K, Osteryoung R A. J Electroanal Chem, 1981, 129: 159

12 Aoki K, Shimizu K, Osteryoung R A. J Electroanal Chem, 1981, 129: 171

13 Briss V I, Wright G A. Electrochim Acta, 1981, 26: 1809

14 Briss V I, Wright G A. Electrochim Acta, 1982, 27: 1

15 Horanyi G, Vertes G. Electrochim Acta, 1986, 31: 1663

16 Hepel M, Bruckenstein S, Tang G C. J Electroanal Chem, 1989, 261: 389

17 Hatchett D W, Gao X, Catron S W, White H S. J Phys Chem, 1996, 100: 331

18 Vericat C, Vela M E, Gago J, Salvarezza R C. Electrochim Acta, 2004, 49: 3643

19 Dryhurst G, Kadish K, Scheller F, Renneberg R. Biological Electrochemistry, Vol 1. New York: Academic press, 1982. 256

20 Davey M W, Van Montagu M, Inze D, Sanmartin M, Kanellis A, Smirnoff N, Benzie I J J, Strain J J, Favell D, Fletcher J. $J$ Sci Food Agric, 2000, 860: 825

21 Schrammel A, Koesling D, Schmidt K, Mayer B. Cardiovasc Res, 2000, 47: 602

22 Harris D C. Quantitative Chemical Analysis. 7th Ed. New York: W.H. Freeman and Company, 2007 